\title{
Comparison of two rotary systems in bacteria/lps removal from endodontic infections: randomized clinical trial
}

\author{
Camila Ambrósio Dias MACHADO(a) \\ Amanda Caselato Andolfatto \\ SOUZA(a) \\ Caroline LOUREIRO(a) \\ Frederico Canato MARTINHO(b) (D) \\ Luciano Tavares Ângelo CINTRA(a) \\ Eloi DEZAN JUNIOR(a) (iD \\ Rogério de Castilho JACINTO(a) \\ (a) Universidade Estadual Paulista - Unesp, \\ School of Dentistry, Endodontic Division, \\ Aracatuba, São Paulo, SP, Brazil. \\ (b) University of Maryland, Baltimore School of \\ Dentistry, Baltimore, MD, USA.
}

Declaration of Interests: The authors certify that they have no commercial or associative interest that represents a conflict of interest in connection with the manuscript.

Corresponding Author:

Rogério de Castilho Jacinto

E-mail: rogerio.castilho@unesp.br

Submitted: October 25, 2018

Accepted for publication: March 26, 2019

Last revision: April 16, 2019
Abstract: This clinical study compared the effectiveness of two rotary systems: HyFlex CM (Coltene-Whaledent, Altstetten, Switzerland) and ProTaper Next (Dentsply Sirona, Ballaigues, Switzerland) on the removal of cultivable bacteria and endotoxins from primarily infected root canals. This study was designed as a randomized single-blinded, 2-arm, clinical trial. Twenty-four primarily infected root canals were selected and randomly divided into 2 groups: HyFlex CM $(n=12)$; and ProTaper Next $(n=12)$. Samples were collected before and after the biomechanical preparation and inoculated in specific flasks. Irrigation was performed using $2.5 \%$ sodium hypochlorite. A kinetic turbidimetric lysate assay of limulus amoebocytes was used to quantify endotoxins. Microbiological culture technique was used to determine the count of bacterial colony forming units $(\mathrm{CFU} / \mathrm{mL})$. Data collected were statistically analyzed using SigmaPlot 12.0 for Windows. The Two-Way ANOVA statistical test was performed and the level of significance was $5 \%$. In the samples before the biomechanical preparation, cultivable bacteria and endotoxins were evidenced in $100 \%$ of the cases. The culture analysis revealed that there was no statistically significant difference in the bacterial reduction between the two instrumentation systems. Endotoxins were present in $100 \%$ of the canals after instrumentation and there was no statistical difference between the two systems in endotoxin reduction. Thus, it was concluded that both instrumentation systems were effective in reducing root canal bacteria and endotoxins with primary endodontic infection and that there was no statistical difference between them. However, no system was able to eliminate $100 \%$ of the bacteria and their by-products.

Keywords: Endotoxins; Bacteria; Endodontics; Disinfection.

\section{Introduction}

The main objective of the endodontic therapy is the reduction of bacteria and their byproducts such as Lipopolysaccharides (LPS), which are responsible for the development of apical diseases. ${ }^{1}$ LPS, released during division or rupture of the bacterial cell ${ }^{2,3}$ are detected in $100 \%$ of root canal infections, playing a key role in triggering inflammation and subsequent release of inflammatory mediators, ${ }^{4}$ and consequently, should be eliminated during root canal instrumentation. 
The use of nickel-titanium rotary files has become a standard technique for providing faster procedures, ${ }^{5,6}$ more centered preparations, ${ }^{7,8}$ and less apical extrusion of debris. ${ }^{9}$ Due to its super elasticity, it has advantages over stainless steel files such as flexibility, and a lower number of steps. The flexibility of these files reduces the incidence of procedural errors, increasing success rates in endodontic treatment compared to conventional techniques. ${ }^{10,11,12}$

HyFlex CM are NiTi rotary instruments with controlled memory (CM) (Coltene-Whaledent, Altstätten, Switzerland) produced from a single thermal process ${ }^{13}$ and changes in $\mathrm{Ni}$ amounts (CM includes $52.1 \% \mathrm{Ni}$, versus $54.2-56.2 \% \mathrm{Ni}$ by weight of the conventional alloys). This treatment gives HyFlex CM (HCM) instruments greater flexibility compared to conventional NiTi instruments. ${ }^{14}$

ProTaper Next (PTN) (Dentsply Sirona, Ballaigues, Switzerland) is a system consisting of three instruments made of a single NiTi alloy and M-wire alloy manufactured through a heat treatment process, and incorporates a variable conical design and a single mass of displacement of rotation, which improves the resistance and flexibility throughout its active part. ${ }^{15}$

LPS act on the synthesis and release of cytokines, which activates osteoclasts, therefore stimulating bone resorption in the process periapical lesions development. ${ }^{16}$ Thus, the removal of bacteria and their by-products must be accomplished by instrumentation of the infected canal walls. Previous studies ${ }^{17,18}$ have shown that the preparation of root canals with rotary system is capable of achieving a reduction of more than $90 \%$ of the bacteria and the endotoxin load (range of $99.41 \%$ to $99,93 \%$ for bacteria and $95,15 \%$ to $98,06 \%$ for endotoxin) of infected root canals. Neelakantan et al. ${ }^{19}$ observed that there is no significant difference between instrumentation techniques in the elimination of endotoxins. However, PTN and HCM were not validated yet with clinical studies evaluating their effectiveness in reducing bacteria and LPS. To date there is no instrumentation system that has proven to be $100 \%$ effective against bacteria and endotoxins in root canal infection. Therefore, there is a need for instruments with higher cleaning capacity, as well as flexibility, durability, ease of use and safety. PTN and HCM are rotary instruments made by thermomechanical treatment of $\mathrm{Ni}$-Ti alloys, representing the $\mathrm{M}$-wire and $\mathrm{CM}$-wire alloys, respectively. In view of the fact that the HCM instruments are made of CM-controlled memory wires, having a superior flexibility compared to other instruments made of M-wire, and the PTN incorporate a variable taper design and a single mass rotational displacement, it is believed that these systems can reach all the walls of the root canal, improving the ability to remove bacteria and endotoxins.

Therefore, the aim of this clinical study was to compare the effectiveness of two rotary systems: HyFlex CM (Coltene-Whaledent, Altstetten, Switzerland) and ProTaper Next (Dentsply Sirona, Ballaigues, Switzerland) on the removal of cultivable bacteria and endotoxins from primarily infected root canals. The null hypothesis tested is that there are no differences in bacterial and endotoxin reduction between the two systems tested.

\section{Methodology}

This study was designed as a randomized singleblinded, 2-arm, clinical trial, which was registered at the "Registro Brasileiro de Ensaios Clínicos - REBEC" website under the registration number RBR-72cyh7. The report followed the CONSORT (Consolidated Standards of Reporting Trials) guidelines. The minimum sample size was determined as 12 teeth per group, based on a mean difference of $10 \%$ in the result between the groups and power $=0.80(\mathrm{p}<0.05)$. Randomization, allocation, concealment and blinding: a random allocation sequence was generated by an external person. This sequence was placed in opaque and sealed envelopes. Each envelope included the randomization code for each patient, which was only revealed at the time of biomechanical preparation. Clinical procedures were performed by an endodontic specialist. The study was not operator blinded because of the structural differences and number of files between the two systems evaluated. However, data analysis was performed by a researcher (RCJ) who was blind to the treatment group. Blinding of patients is not relevant as this is not a patient-reported outcome measure.

Twenty-four patients who sought the Dental School of the São Paulo State University (UNESP), Araçatuba, 
Brazil, requiring primary endodontic treatment were included in the present study. A detailed dental history was obtained from each patient. Those who had received antibiotic treatment during the last 3 months or who had any systemic disease were excluded, following previously published protocol. $17,18,20,21,22,23,24,25$ The Human Research Ethics Committee of Araçatuba Dental School approved the research protocol describing the sample collection for this investigation (CAAE: 55513016.8.0000.5420), and all volunteer patients signed an informed consent form.

Only maxillary molars or premolars with primary endodontic infection and without periodontal pockets deeper than $4 \mathrm{~mm}$ were selected. Only the palatal canal of each tooth was sampled. None of the patients reported spontaneous pain and sinus tract. Teeth that could not be isolated with a rubber dam and teeth in which the paper point could not be introduced in the canal were excluded. The following clinical/radiographic features were found in root canals with primary endodontic infections registered: pain on palpation (10/24), tenderness to percussion $(13 / 24)$, and a radiolucent area greater than $3 \mathrm{~mm}$ in size $(09 / 24)$.

Files, instruments, and all materials used in this study were treated with Cobalt ${ }^{60}$ gamma radiation (20 kGy for 6 hours) for sterilization and the elimination of pre-existing endotoxins (IPEN; Instituto de Pesquisas Energéticas e Nucleares, São Paulo, SP, Brasil). The method used for disinfection of the operative field was previously described. ${ }^{20,26}$ Briefly, the teeth were isolated with a rubber dam, and the crown and surrounding structures were disinfected with $30 \%$ hydrogen peroxide (volume/volume for 30 seconds) followed by $2.5 \%$ sodium hypochlorite $(\mathrm{NaOCl})$ for the same period of time, and then inactivated with $5 \%$ sodium thiosulfate. The sterility of the external surfaces of the crown was checked by taking a swab sample from the crown surface and streaking it onto blood agar plates, which were then incubated both aerobically and anaerobically.

A 2-stage access cavity preparation was made without the use of water spray but under manual irrigation with sterile/apyrogenic saline solution and using a sterile/apyrogenic high-speed diamond bur. The first stage was performed to promote a major removal of contaminants, including carious lesions and restorations. In the second stage, before entering the pulp chamber, the access cavity was disinfected according to the protocol described previously. All procedures were performed aseptically. After initial access, sterility was also checked, by analyzing a swab sample from the cavity internal surface. The collections were performed in the palatal canal and, when needed, Gattes-Gliden drill was used to remove dentin only at the orifice entrance, before the first sample collection. The first endotoxin sampling was taken by introducing sterile/apyrogenic paper points (size \#15, Dentsply Sirona, Ballaigues, Switzerland) into the apparent length of the root, which was determined radiographically and retained in position for 60 seconds for sampling. Immediately afterwards, the sample was placed in a pyrogen-free glass and immediately suspended in $1 \mathrm{~mL}$ limulus amebocyte lysate (LAL) water, according to the endotoxin dosage by using a kinetic turbidimetric LAL (Lonza, Walkersville, MD) assay. This sampling procedure was repeated with 3 paper points that were pooled in a sterile tube containing $1 \mathrm{~mL}$ Viability Medium Göteborg Agar III (VMGA III) transport medium ${ }^{27}$ for microbial cultivation.

After accessing the pulp chamber and subsequent first endotoxin sampling, teeth were randomly divided into 2 groups: $\operatorname{HCM}(n=12)$ and PTN $(n=12)$. After the first sampling, the root canal length was determined from the preoperative radiograph and confirmed using an apex locator (Root ZXII, J. Morita Corp., Tokyo, Japan). The root canals were then prepared according to the group selection.

All instruments were set into permanent rotation with a 6:1 contra-angle handpiece (Sirona, Bensheim, Germany) powered by a torque-limited electric motor (VDW.Silver Reciproc motor, VDW). The preparation sequences were as described below.

\section{Group HCM}

HCM instruments were used according to the manufacturer's instructions. The first instrument was used in an in-an-out pecking motion of about $3 \mathrm{~mm}$ in amplitude with apical pressure. After 3 pecking motions, the instrument was removed from the canal and cleaned. Next, a size \#15 K-type file was taken to 
the working length (WL) to check whether the canal was patent. These procedures were repeated until the HCM instrument reached the WL $(-1 \mathrm{~mm})$. All HCM instruments were used to the WL of the canals in a gentle in-and-out motion. The instrumentation sequence was as follows: file Step 1 \#25/08 at two thirds of the WL, followed by the file Step 2 \#20/04, Step 3 \#25/04, Step 4 \#20/06, Step 5 \#30/04, and Step 6 size \#40/04 at the WL.

\section{Group PTN}

PTN instruments were used according to the manufacturer's instructions in a gentle in-and-out motion. Afterward, the instrument was removed from the canal and cleaned. Next, a size \#15 K-type file was taken to the WL $(-1 \mathrm{~mm})$ to check whether the canal was patent. The instrumentation sequence was as follows: $\mathrm{X} 1$ instrument at two thirds of the $\mathrm{WL}$, $\mathrm{X} 1$ instrument at the WL $(-1 \mathrm{~mm})$ (taper $=04$, size \#17), X2 instrument at the WL $(-1 \mathrm{~mm})$ (taper $=06$, size \#25), X3 at the WL (-1 mm) (taper $=07$, size \#30).

For both groups irrigation was performed with disposable syringes and 30-G NaviTip needles (Ultradent, South Jordan, UT) by using $5 \mathrm{~mL}$ $2.5 \% \mathrm{NaOCl}$ solution between files. Before the second sampling after instrumentation, $\mathrm{NaOCl}$ was inactivated with $5 \mathrm{~mL}$ sterile $0.5 \%$ sodium thiosulfate during a 1-minute period, which was then removed with $5 \mathrm{~mL}$ sterile/apyrogenic water. Next, a new sampling procedure was performed as described previously. After instrumentation and sample collection, the root canals received calcium hydroxide intracanal medication and after 14 days were filled with Gutta-Percha (Dentsply Sirona [PTN] or VDW [HCM]) and FillApex MTA (Angelus, Londrina, Paraná, Brazil) and then restored with composite resin (3M, Maplewood, Minnesota, EUA).

\section{Determination of cultivable bacterial counts (culturing procedure)}

The method used for culture procedures in the present study was previously reported. ${ }^{18,26,28}$ Briefly, the transport media containing the root canal samples were thoroughly shaken for 60 seconds (Vortex; Marconi, Piracicaba, São Paulo, Brazil). Serial 10-fold dilutions were made up to $10^{-4}$ in tubes containing
Brain Heart Infusion broth (BHI; Himedia, Mumbai, Maharashtra, India). Fifty microliters of the serial dilutions were plated onto 5\% defibrinated sheep Brain Heart Infusion agar (BHI agar; Kasvi, São José dos Pinhais, PR, Brazil) by using sterile plastic spreaders to culture nonselectively obligate anaerobes and facultative anaerobes. The plates were incubated at $37^{\circ} \mathrm{C}$ in anaerobic atmosphere for up to 14 days. After this period, colony-forming units $(\mathrm{CFU} / \mathrm{mL})$ were visually quantified for each plate.

\section{Determination of endotoxin concentration (kinetic turbidimetric LAL assay)}

The kinetic turbidimetric LAL assay Pyrogent-5000 (Lonza, Walkersville, EUA) used for quantification of endotoxins was previously described ${ }^{(21,22)}$. Briefly, for the test, $100 \mathrm{~mL}$ apyrogenic water (reaction blank), the 5 standard endotoxin solutions (0.01-100 endotoxin units $[\mathrm{EU}] / \mathrm{mL}$ ), root canal samples, and positive controls (each root canal sample contaminated with a known concentration of endotoxin [10 EU/mL]) were added to a 96-well apyrogenic plate. The tests were performed in duplicate. The plate was incubated at $37^{\circ} \mathrm{C} \pm 1^{\circ} \mathrm{C}$ for 10 minutes in the microplate reader BioTek ELx808 (Lonza, Walkersville, MD, EUA), which was coupled to a microcomputer by means of the WinKQCL software. Next, $100 \mu \mathrm{L}$ Pyrogent-5000 reconstituted reagent was added to each well. After the beginning of the kinetic test, the software continuously monitored absorbance at $340 \mathrm{~nm}$ in each microplate well and automatically calculated the $\log / \log$ linear correlation between the reaction time of each standard solution and the corresponding endotoxin concentration.

\section{Statistical analysis}

The data collected (CFU/mL and endotoxin concentrations EU/mL) were statistically analyzed by using Sigma Plot 12.0 for Windows (Systat Software Inc, San Jose, CA). The Shapiro-Wilk test showed that the variables studied had normal distribution. The data also presented a homogeneous distribution. A comparison between different sampling times and the root canal treatment groups was performed by using the Two-Way ANOVA test. The significance level was always set at $5 \%(p<0.05)$. 


\section{Results}

A total of 24 patients, being 8 males and 16 females, participated in this study. Random allocation of subjects resulted in 12 patients in the PTN group (4 males and 8 females) and 12 patients in the HCM

Table 1. Demographic data of the study.

\begin{tabular}{lcc}
\hline Group & Male/Female & Age (years) \\
\hline PTN & $04 / 08$ & $41.58 \pm 12.09$ \\
HCM & $04 / 08$ & $44.25 \pm 15.95$ \\
Total & $08 / 16$ & $42.92 \pm 15.78$ \\
\hline
\end{tabular}

PTN, ProTaper Next; HCM, HyFlex CM. group (4 males and 8 females) (Table 1). The mean age of patients in PTN group was $41.58 \pm 12.09$ whilst it was $44.25 \pm 15.95$ in the HCM group (Table 1). Recruitment was performed from March/2017 until May/2018. The trial was completed in May/2018. Fig. 1 shows the participant flow chart.

Table 2 shows the number of $\mathrm{CFU} / \mathrm{mL}$ and the concentration of Endotoxins (EU/mL) found before (S1) and after (S2) the instrumentation with PTN or HCM. Concerning the bacterial culture, the presence of bacteria was verified in $100 \%$ of the initial samples (S1) in the two systems. At S2, there was no bacterial growth in 4 of 12 PTN samples and 5 of $12 \mathrm{HCM}$ samples. Bacterial culture analysis revealed no

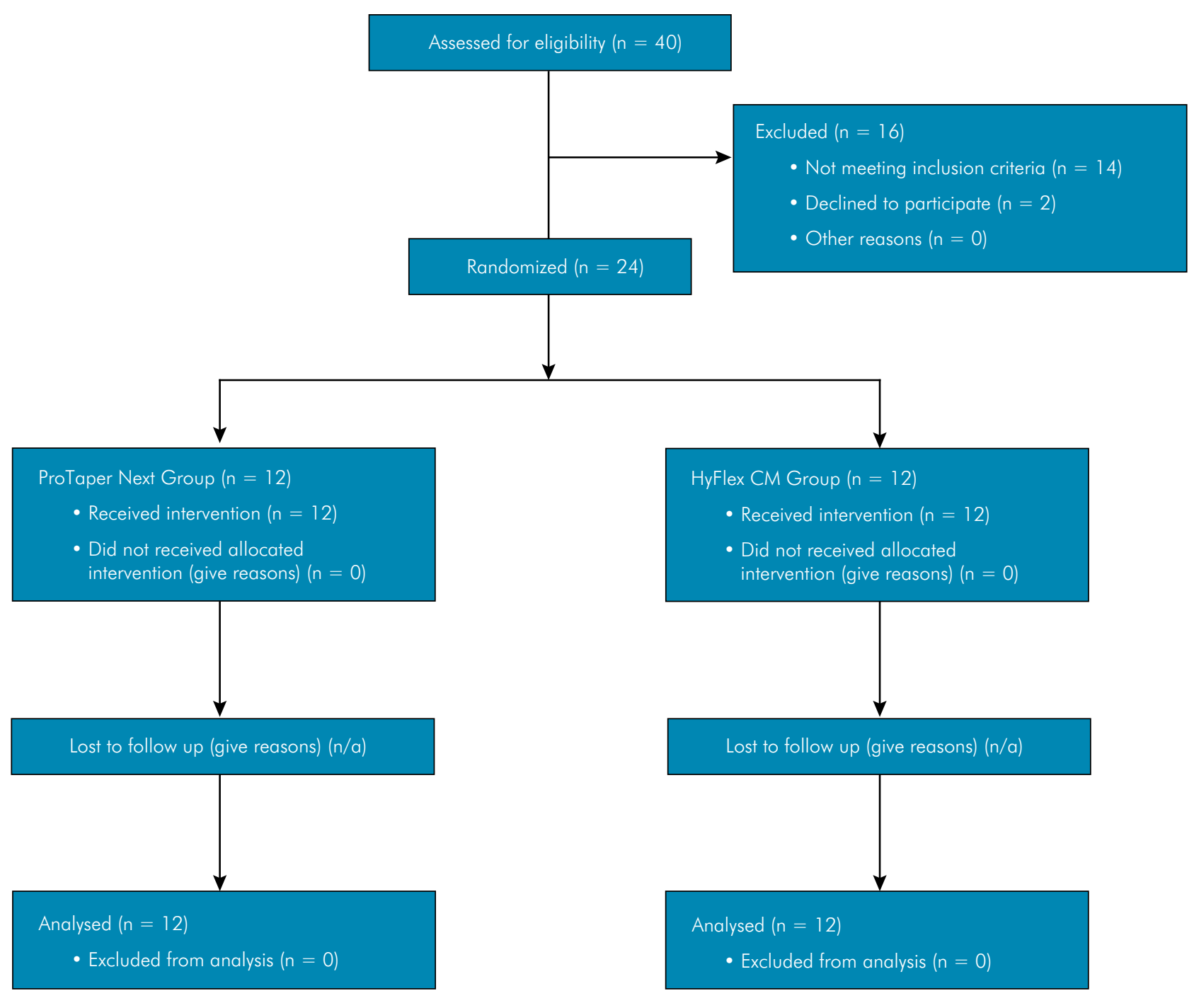

Figure 1. Consolidated standards of reporting trials flow chart. 
statistically significant difference between the two instrumentation systems $(\mathrm{p}=0.226)$ in the reduction of root canal bacteria with primary endodontic infections. In relation to endotoxin concentrations, its presence was detected in $100 \%$ of the samples collected before and after root canal instrumentation. However, there was no statistically significant difference between the two instrumentation systems in reducing endotoxin concentration $(p=0.240)$. The percentage values of bacterial and endotoxin reductions found in groups tested are shown in Table 3.

\section{Discussion}

The present clinical trial compared the effectiveness of two rotary systems (PTN and HCM) on the removal of cultivable bacteria and endotoxins from primarily infected root canals. The PTN files presents larger taper compared to the HCM files, and its decentralized core design promotes less contact of the instrument with the root canal walls, ${ }^{29}$ favoring a greater extrusion of debris in the coronal direction. ${ }^{30} \mathrm{HCM}$ has a great flexibility when compared in to other instruments made of super-elastic wires. Instruments with great flexibility have their cutting power diminished since

Table 3. Percentage reduction values of cultivable bacteria and endotoxins found in primarily infected root canal after PTN or HCM instrumentation.

\begin{tabular}{lcc}
\hline Groups & Cultivable bacteria & Endotoxins \\
\hline PTN & $98.70 \%$ & $89.20 \%$ \\
HCM & $99.80 \%$ & $93.10 \%$ \\
\hline
\end{tabular}

PTN, ProTaper Next; HCM, HyFlex CM. it deforms easily in the walls of the root canals against slight pressure, ${ }^{31}$ which could influence the bacterial and LPS reduction. The results demonstrated that the two instrumentation systems were effective in the reduction of bacteria and endotoxins of root canals with primary endodontic infections. The data are in accordance with other studies that also demonstrated bacterial reduction above $95 \%$ with mechanized systems. ${ }^{18,32}$ However, none of the systems were able to completely eliminate bacteria and endotoxins.

In our study, we observed the presence of negative culture in the samples in part of the patients after the instrumentation. Although $\mathrm{CFU} / \mathrm{mL}$ counting is a reliable method to evaluate the cleaning ability of endodontic instrumentation, one should take into account several limitations that may have led to samples with negative bacterial cultures, which does not mean that bacteria were not present. Thus, these negative cultures could be a consequence of a very low level of bacteria that possibly could not be detected; limitations related to the sampling procedures, to the culture techniques, or to the presence of bacteria that cannot yet be cultured..$^{33}$

It is known that pulp and periapical diseases are mainly caused by bacteria and their byproducts. ${ }^{1}$ Endotoxins are related to the triggering of inflammation and subsequent release of inflammatory mediators. ${ }^{4,34}$ In the present study, the detection of endotoxins was performed in $100 \%$ of the samples, in accordance with previous studies. ${ }^{23,24,25,28}$ Endodontic files systems reduced endotoxins by more than $89 \%$, with no statistical difference between them. However, endotoxins were detected in all cases after instrumentation, regardless of the system used. It is important that the chemomechanical preparation focus

Table 2. Effectiveness of PTN and HCM for the removal of cultivable bacteria $(\mathrm{CFU} / \mathrm{mL}$ ) and endotoxins (EU/mL) from primarily infected root canals.

\begin{tabular}{|c|c|c|c|c|}
\hline \multirow{2}{*}{ Groups } & \multicolumn{2}{|c|}{ Cultivable bacteria (CFU/mL) } & \multicolumn{2}{|c|}{ Endotoxins $(\mathrm{EU} / \mathrm{mL})$} \\
\hline & Before treatment $(\mathrm{S} 1)^{\mathrm{a}}$ & After treatment $(\mathrm{S} 2)^{\mathrm{b}}$ & Before treatment $(S 1)^{a}$ & After treatment $(\mathrm{S} 2)^{\mathrm{b}}$ \\
\hline \multirow{2}{*}{ PTN } & $3.6 \times 10^{6}$ & $4.4 \times 10^{4}$ & 27.50 & 2.95 \\
\hline & $\left(2.0 \times 10^{4}-3.0 \times 10^{7}\right)$ & $\left(0-4.0 \times 10^{5}\right)$ & $(2.34-100)$ & $(0.24-7.63)$ \\
\hline \multirow{2}{*}{$\mathrm{HCM}$} & $1.2 \times 10^{6}$ & $1.7 \times 10^{3}$ & 26.38 & 1.82 \\
\hline & $\left(5.0-8.6 \times 10^{6}\right)$ & $\left(0-1.7 \times 10^{4}\right)$ & (1.63-122) & $(0.29-7.10)$ \\
\hline
\end{tabular}

CFUs, colony-forming units; EUs, endotoxin units. PTN, ProTaper Next; HCM, HyFlex CM. Media, minimum and maximum of cultivable bacteria and endotoxins found in primarily infected root canals. Different letters indicate significant statistical differences between initial and final sampling (Fisher LSD Method, $\mathrm{p}<0.05$ ). 
on reducing LPS to a level that initiates periradicular tissue healing, rather than just reducing/eliminating microorganisms and infected tissues, ${ }^{24}$ as even small amounts of endotoxin are capable of triggering the inflammatory osteolysis by inducing the release of pro-inflammatory cytokines and MMP-1 from macrophages. ${ }^{35}$ Such a threshold value of the infectious content remains unknown. ${ }^{19}$ However, it is expected that in the absence of living gram-negative cells to maintain LPS levels, its action would only be transient and unlikely to impact treatment outcome.

The endotoxin values found are in agreement with previous studies that used the Pyrogent-5000 turbidimetric LAL kinetic test (Lonza). ${ }^{36,37}$ LAL tests for the quantification of endotoxins use a coagulation cascade that is activated by the presence of endotoxin. ${ }^{21}$ In the chromogenic tests (chromogenic endpoint [QCL test] and kinetic chromogenic [KQCL test] assays) this presence is represented by the yellow color intensity of the samples while in the turbidimetric test (Pyrogent-5000) the measurement is by turbidity. In both, higher amount of endotoxins, more yellowish or turbid the solutions with the samples are presented. According to Martinho et al. ${ }^{21}$ the turbidimetric kinetic method is one of the most useful tests to quantify the endotoxins of root canal infections, being an accurate test with good reproducibility, as well as the KQCL test. Whereas, QCL test is limited in relation to its sensitivity. ${ }^{21}$

In the present study, molars and pre-molars with primary endodontic infections and chronic apical periodontitis were used, in order to obtain a sample with similar microbiological characteristics. To perform the initial collection without previous instrumentation, the palatal canal was chosen due to its larger anatomy, even so, a pilot study showed that dentinal removal was necessary in order to allow the introduction of the paper cone until the apparent tooth length, which was accomplished by using Gattes-Gliden drill to remove dentin only at the orifice entrance.

Conventional needle irrigation was used here instead of ultrasonic activation. It has been shown that ultrasonic activation is more effective than needle irrigation in removing bacteria from root canals in a clinical setting. ${ }^{38}$ Therefore, if activation of the irrigating solution was used it could influenced the results when comparing both instrument systems.
The HCM system presents a greater number of instruments than the PTN systems and consequently, a different volume of irrigation was used during the biomechanical preparation since the root canals were irrigated with each file change, respecting the clinical protocol. A systematic review has proved that when irrigating regimens are kept constant, the type of instrument used does not have an influence on endotoxin reduction during root canal treatment. ${ }^{19}$ Nevertheless, no statistical difference was observed between both instrument systems. Another difference between the protocols of instrumentation evaluated is the final tip diameter of the last instrument used for each system: while HCM presents size \#40/04 (step 6), PTN has size \#30/07 (X3), which promotes further widening of the zone suggesting greater cleanliness of this region. ${ }^{37}$ Nevertheless, no statistical difference was found in the reduction of bacteria and endotoxins between the two systems of instrumentation and none of the systems were able to eliminate $100 \%$ of the bacteria and their byproducts, which could be related to untouched canal areas. Therefore, the difference found between both protocols regarding the apical preparation diameter, and also their design features, did not affect the outcome of the root canal bacterial and endotoxin disinfection.

Given the results of the present study, where bacteria and endotoxins were not completely eliminated regardless of the system used, it is important to highlight the relevance of using intracanal medication as an aid in the disinfection of infected root canals. Recent studies showed that calcium hydroxide-based intracanal medication reduces 99.5\% of microorganisms in persistent infections, in addition to reducing pro-inflammatory cytokines. ${ }^{39}$ Other studies confirm the ability of calcium hydroxidebased medication to eliminate endotoxins at different time periods of action. ${ }^{40}$

\section{Conclusion}

Thus, it could be concluded that both systems were able to eliminate large amounts of bacteria and endotoxins from the root canals with primary endodontic infections, although remnants of endotoxins were found in all cases. 
- Comparison of two rotary systems in bacteria/lps removal from endodontic infections: randomized clinical trial

\section{Acknowledgments}

This work was supported by the Brazilian agencies Fapesp (2016/08157-4), and Capes. Supported by “Edital Primeiros Projetos Unesp-Prope" (09/2016). We are thankful to Dr. Brenda P. F. A. Gomes and Maicon R Z Passini, from the Piracicaba Dental School-UNICAMP and to Ana Regina de Oliveira Polay and Melissa Justino for technical support.

\section{References}

1. Kakehashi S, Stanley HR, Fitzgerald RJ. The effects of surgical exposures of dental pulps in germ-free and conventional laboratory rats. Oral Surg Oral Med Oral Pathol. 1965 Sep;20(3):340-9. https://doi.org/10.1016/0030-4220(65)90166-0

2. Schein B, Schilder H. Endotoxin content in endodontically involved teeth. J Endod. 1975 Jan;1(1):19-21. https://doi.org/10.1016/S0099-2399(75)80244-5

3. Pitts DL, Williams BL, Morton TH Jr. Investigation of the role of endotoxin in periapical inflammation. J Endod. 1982 Jan;8(1):10-8. https://doi.org/10.1016/S0099-2399(82)80310-5

4. Oliveira LD, Carvalho CA, Carvalho AS, Alves JS, Valera MC, Jorge AO. Efficacy of endodontic treatment for endotoxin reduction in primarily infected root canals and evaluation of cytotoxic effects. J Endod. 2012 Aug;38(8):1053-7. https://doi.org/10.1016/i.joen.2012.04.015

5. Guelzow A, Stamm O, Martus P, Kielbassa AM. Comparative study of six rotary nickel-titanium systems and hand instrumentation for root canal preparation. Int Endod J. 2005 Oct;38(10):743-52. https://doi.org/10.1111/i.1365-2591.2005.01010.x

6. Yin X, Cheung GS, Zhang C, Masuda YM, Kimura Y, Matsumoto K. Micro-computed tomographic comparison of nickel-titanium rotary versus traditional instruments in C-shaped root canal system. J Endod. 2010 Apr;36(4):708-12. https://doi.org/10.1016/i.joen.2010.01.003

7. Taşdemir T, Aydemir H, Inan U, Unal O. Canal preparation with Hero 642 rotary Ni-Ti instruments compared with stainless steel hand K-file assessed using computed tomography. Int Endod J. 2005 Jun;38(6):402-8. https://doi.org/10.1111/j.1365-2591.2005.00961.x

8. Aguiar CM, de Andrade Mendes D, Câmara AC, de Figueiredo JA. Evaluation of the centreing ability of the ProTaper Universal rotary system in curved roots in comparison to Nitiflex files. Aust Endod J. 2009 Dec;35(3):174-9. https://doi.org/10.1111/j.1747-4477.2009.00168.x

9. Madhusudhana K, Mathew VB, Reddy NM. Apical extrusion of debris and irrigants using hand and three rotary instrumentation systems: an in vitro study. Contemp Clin Dent. 2010 Oct;1(4):234-6. https://doi.org/10.4103/0976-237X.76390

10. Sonntag D, Ott M, Kook K, Stachniss V. Root canal preparation with the NiTi systems K3, Mtwo and ProTaper. Aust Endod J. 2007 Aug;33(2):73-81. https://doi.org/10.1111/j.1747-4477.2007.00062.x

11. Schäfer E, Erler M, Dammaschke T. Comparative study on the shaping ability and cleaning efficiency of rotary Mtwo instruments. Part 1. Shaping ability in simulated curved canals. Int Endod J. 2006 Mar;39(3):196-202. https://doi.org/10.1111/j.1365-2591.2006.01074.x

12. Schäfer E, Erler M, Dammaschke T. Comparative study on the shaping ability and cleaning efficiency of rotary Mtwo instruments. Part 2. Cleaning effectiveness and shaping ability in severely curved root canals of extracted teeth. Int Endod J. 2006 Mar;39(3):203-12. https://doi.org/10.1111/j.1365-2591.2006.01075.x

13. Gutmann JL, Gao Y. Alteration in the inherent metallic and surface properties of nickel-titanium root canal instruments to enhance performance, durability and safety: a focused review. Int Endod J. 2012 Feb;45(2):113-28. https://doi.org/10.1111/j.1365-2591.2011.01957.x

14. Testarelli L, Plotino G, Al-Sudani D, Vincenzi V, Giansiracusa A, Grande NM, et al. Bending properties of a new nickel-titanium alloy with a lower percent by weight of nickel. J Endod. 2011 Sep;37(9):1293-5. https://doi.org/10.1016/i.joen.2011.05.023

15. De-Deus G, Belladonna FG, Souza EM, Silva EJ, Neves AA, Alves H, et al. Micro-computed Tomographic Assessment on the Effect of ProTaper Next and Twisted File Adaptive Systems on Dentinal Cracks. J Endod. 2015 Jul;41(7):1116-9. https://doi.org/10.1016/i.joen.2015.02.012

16. Cardoso FG, Ferreira NS, Martinho FC, Nascimento GG, Manhães LR Jr, Rocco MA, et al. Correlation between Volume of Apical Periodontitis Determined by Cone-beam Computed Tomography Analysis and Endotoxin Levels Found in Primary Root Canal Infection. J Endod. 2015 Jul;41(7):1015-9. https://doi.org/10.1016/i.joen.2015.02.005

17. Martinho FC, Chiesa WM, Marinho AC, Zaia AA, Ferraz CC, Almeida JF, et al. Clinical investigation of the efficacy of chemomechanical preparation with rotary nickel-titanium files for removal of endotoxin from primarily infected root canals. J Endod. 2010 Nov;36(11):1766-9. https://doi.org/10.1016/j.joen.2010.08.019 
18. Martinho FC, Gomes AP, Fernandes AM, Ferreira NS, Endo MS, Freitas LF, et al. Clinical comparison of the effectiveness of single-file reciprocating systems and rotary systems for removal of endotoxins and cultivable bacteria from primarily infected root canals. J Endod. 2014 May;40(5):625-9. https://doi.org/10.1016/i.joen.2013.12.006

19. Neelakantan P, Ahmed HM, Chang JW, Nabhan MS, Wei X, Cheung GS, et al. Effect of instrumentation systems on endotoxin reduction from root canal systems: A systematic review of clinical studies and meta-analysis. Aust Endod J. 2018 Dec. https://doi.org/10.1111/aej.12333

20. Gomes BP, Pinheiro ET, Gadê-Neto CR, Sousa EL, Ferraz CC, Zaia AA, et al. Microbiological examination of infected dental root canals. Oral Microbiol Immunol. 2004 Apr;19(2):71-6. https://doi.org/10.1046/i.0902-0055.2003.00116.x

21. Martinho FC, Chiesa WM, Zaia AA, Ferraz CC, Almeida JF, Souza-Filho FJ, et al. Comparison of endotoxin levels in previous studies on primary endodontic infections. J Endod. 2011 Feb;37(2):163-7. https://doi.org/10.1016/i.joen.2010.11.020

22. Endo MS, Martinho FC, Zaia AA, Ferraz CC, Almeida JF, Gomes BP. Quantification of cultivable bacteria and endotoxin in post-treatment apical periodontitis before and after chemo-mechanical preparation. Eur J Clin Microbiol Infect Dis. 2012 Oct;31(10):2575-83. https://doi.org/10.1007/s10096-012-1598-6

23. Martinho FC, Gomes BP. Quantification of endotoxins and cultivable bacteria in root canal infection before and after chemomechanical preparation with 2.5\% sodium hypochlorite. J Endod. 2008 Mar;34(3):268-72. https://doi.org/10.1016/i.joen.2007.11.015

24. Gomes BP, Martinho FC, Vianna ME. Comparison of $2.5 \%$ sodium hypochlorite and $2 \%$ chlorhexidine gel on oral bacterial lipopolysaccharide reduction from primarily infected root canals. J Endod. 2009 Oct;35(10):1350-3. https://doi.org/10.1016/i.joen.2009.06.011

25. Vianna ME, Horz HP, Conrads G, Zaia AA, Souza-Filho FJ, Gomes BP. Effect of root canal procedures on endotoxins and endodontic pathogens. Oral Microbiol Immunol. 2007 Dec;22(6):411-8. https://doi.org/10.1111/j.1399-302X.2007.00379.x

26. Jacinto RC, Gomes BP, Ferraz CC, Zaia AA, Filho FJ. Microbiological analysis of infected root canals from symptomatic and asymptomatic teeth with periapical periodontitis and the antimicrobial susceptibility of some isolated anaerobic bacteria. Oral Microbiol Immunol. 2003 Oct;18(5):285-92. https://doi.org/10.1034/i.1399-302X.2003.00078.x

27. Dahlén G, Pipattanagovit $P$, Rosling B, Möller AJ. A comparison of two transport media for saliva and subgingival samples. Oral Microbiol Immunol. 1993 Dec;8(6):375-82. https://doi.org/10.1111/j.1399-302X.1993.tb00614.x

28. Jacinto RC, Gomes BP, Shah HN, Ferraz CC, Zaia AA, Souza-Filho FJ. Quantification of endotoxins in necrotic root canals from symptomatic and asymptomatic teeth. J Med Microbiol. 2005 Aug;54(Pt 8):777-83. https://doi.org/10.1099/imm.0.45976-0

29. Elnaghy AM. Cyclic fatigue resistance of ProTaper Next nickel-titanium rotary files. Int Endod J. 2014 Nov;47(11):1034-9. https://doi.org/10.1111/iej.12244 PMID:24392730

30. Koçak MM, Çiçek E, Koçak S, Sağlam BC, Yılmaz N. Apical extrusion of debris using ProTaper Universal and ProTaper Next rotary systems. Int Endod J. 2015 Mar;48(3):283-6. https://doi.org/10.1111/iej.12313

31. Bergmans L, Van Cleynenbreugel J, Wevers M, Lambrechts P. Mechanical root canal preparation with NiTi rotary instruments: rationale, performance and safety. Status report for the American Journal of Dentistry. Am J Dent. 2001 Oct;14(5):324-33.

32. Tewari RK, Ali S, Mishra SK, Kumar A, Andrabi SM, Zoya A, et al. Mechanical reduction of the intracanal Enterococcus faecalis population by Hyflex CM, K3XF, ProTaper Next, and two manual instrument systems: an in vitro comparative study. J Investig Clin Dent. 2016 May;7(2):168-73. https://doi.org/10.1111/jicd.12136

33. Vianna ME, Horz HP, Conrads G, Feres M, Gomes BP. Comparative analysis of endodontic pathogens using checkerboard hybridization in relation to culture. Oral Microbiol Immunol. 2008 Aug;23(4):282-90. https://doi.org/10.1111/j.1399-302X.2007.00425.x

34. Huang W, Zhao L, Jia Y, Chen JJ, Wu YF. [Effect of Porphyromonas gingivalis lipopolysacchearide on the expression of CC chemokine receptor 2 in monocytes]. Zhonghua Kou Qiang Yi Xue Za Zhi. 2013 Jul;48(7):393-7. Chinese.

35. Hong CY, Lin SK, Kok SH, Cheng SJ, Lee MS, Wang TM, et al. The role of lipopolysaccharide in infectious bone resorption of periapical lesion. J Oral Pathol Med. 2004 Mar;33(3):162-9. https://doi.org/10.1111/i.0904-2512.2004.00045.x

36. Marinho AC, Martinho FC, Gonçalves LM, Rabang HR, Gomes BP. Does the Reciproc file remove root canal bacteria and endotoxins as effectively as multifile rotary systems? Int Endod J. 2015 Jun;48(6):542-8. https://doi.org/10.1111/iej.12346

37. Marinho AC, Martinho FC, Zaia AA, Ferraz CC, Gomes BP. Influence of the apical enlargement size on the endotoxin level reduction of dental root canals. J Appl Oral Sci. 2012 Nov-Dec;20(6):661-6. https://doi.org/10.1590/S1678-77572012000600012

38. Nakamura VC, Pinheiro ET, Prado LC, Silveira AC, Carvalho AP, Mayer MP, et al. Effect of ultrasonic activation on the reduction of bacteria and endotoxins in root canals: a randomized clinical trial. Int Endod J. 2018 Jan;51 Suppl 1:e12-22. https://doi.org/10.1111/iej.12783

39. Barbosa-Ribeiro M, Arruda-Vasconcelos R, de-Jesus-Soares A, Zaia AA, Ferraz CC, Almeida JF, et al. Effectiveness of calcium hydroxide-based intracanal medication on infectious/inflammatory contents in teeth with post-treatment apical periodontitis. Clin Oral Investig. 2018 Oct. https://doi.org/10.1007/s00784-018-2719-0

40. Marinho AC, To TT, Darveau RP, Gomes BP. Detection and function of lipopolysaccharide and its purified lipid A after treatment with auxiliary chemical substances and calcium hydroxide dressings used in root canal treatment. Int Endod J. 2018 Oct;51(10):1118-29. https://doi.org/10.1111/iej.12920 